\title{
Um Estudo Sobre a Divulgação das Informações das Práticas de Governança Corporativa nos Sítios das Entidades Fechadas de Previdência Complementar
}

\author{
A Study of Information Disclosure of Corporate Governance Practices in the Sites of Closed \\ Pension Funds
}

\section{Jorge Expedito de Gusmão Lopes}

Doutor em Educação pela University of Miami

Professor do Mestrado de Ciências Contábeis da UFPE

Endereço: Rua P. Carapuceiro 273/501, Boa Viagem

CEP 51020-280 - Recife/PE - Brasil

E-mail : professorjorgelopes@gmail.com

Telefone: (81) 8897-7989

\section{Sheila Sayuri Kataoka}

Graduada em Ciências Contábeis

Mestranda da Universidade Federal de Pernambuco

Endereço: Rua Dr. Manoel de Almeida Belo n 1241 N $^{\circ} 202$, Bairro Novo

CEP: 53.030-030 - Olinda/PE - Brasil.

E-mail: sheilakataoka@ig.com.br

Telefone: (81) 9934-3856

\section{José Francisco Ribeiro Filho}

Doutor em Ciências Contábeis

Professor da Universidade Federal de Pernambuco

Endereço: Rua Leonardo Da Vince - 08 Casa B - Curado II

CEP: Jaboatão dos Guararapes/PE - Brasil

E-mail: francisco.ribeiro@ufpe.br

Telefone:

\section{Marcleide Maria Macêdo Pederneiras}

Mestre em Ciências Contábeis pela Universidade de Brasília

Doutoranda em Administração pelo PROPAD/UFPE- Universidade Federal de Pernambuco

Professora do Curso de Ciências Contábeis da Universidade Federal da Paraíba

Endereço: Rua Telegrafista Cícero Caldas, № 206, Bairro dos Estados

CEP: 58031-040 - João Pessoa/PB - BRASIL

E-mail: marcleide@gmail.com

Telefone: (83) 3224-3407 


\title{
Resumo
}

O objetivo desse artigo foi evidenciar a divulgação de informações das práticas de governança corporativa nos endereços eletrônicos das Entidades Fechadas de Previdência Complementar. Por administrar recursos de terceiros, a adoção de práticas de governança corporativa nessas entidades, é pleiteada como uma forma de aumentar a segurança econômico-financeira e atuarial. Sendo necessária a comunicação com participantes e assistidos visando à transparência na administração. Através do estudo de observação direta investigativa, foi realizada visitação aos sítios das 50 maiores Entidades do país em termos de ativo de investimentos. Com aplicação de um formulário padronizado e tratamento estatístico com base em medidas de posição e dispersão e teste não-paramétrico levantou-se evidências empíricas da relação entre a governança corporativa e a transparência para os usuários. A conclusão encontrada é que as práticas de governança corporativa não estão sendo evidenciadas de forma clara aos participantes e assistidos que buscam as páginas eletrônicas como meio de informação sobre a gestão dos recursos dos planos em que participam.

Palavras-chave: governança corporativa. Fundo de pensão. Informação para usuários.

\begin{abstract}
The purpose here is to highlight the disclosure of corporate governance practices at the websites of Closed Pension Funds. For managing resources of third parties to adopt corporate governance practices in these entities is being claimed as a way to increase economic security and financial and actuarial. Being required to communicate with participants and beneficiaries with the aim of transparency in administration. Through direct observation investigative study was carried out visits to sites of 50 major entities of the country in terms of asset investments. With application of a standardized questionnaire and statistical analysis based on measurements of position and dispersion and non-parametric test rose empirical evidence of the relationship between corporate governance and transparency to users. The conclusion found is that the corporate governance practices are not clearly evident to the participants and beneficiaries who seek the websites as a means of information resource management plans in which they participate.
\end{abstract}

Key words: corporate governance. Pension fund. Information for users.

\section{Introdução}

Há cerca de 30 anos o mundo dos negócios tem passado por grandes transformações. As empresas precisam acompanhar as constantes mudanças que ocorrem nos mercados consumidores internos e externos, uma vez que as mesmas passam a ser avaliadas não apenas pela sua lucratividade e eficiência, mas também, por fatores como governança corporativa, responsabilidade ambiental e fiscal e sua relação direta com a sociedade.

O mecanismo de alinhamento de interesses entre investidores e empresas, a transparência nas ações desenvolvidas, a equidade das informações e a prestação de contas a todos os acionistas formam o necessário ambiente para o desenvolvimento da governança corporativa em uma instituição.

Ao longo desse período, no Brasil, as Entidades Fechadas de Previdência Complementar (EFPC's) muito contribuíram para a evolução da governança corporativa, como acionistas minoritários e, especialmente, participando de blocos de controle de empresas abertas. Entretanto, foi com a Resolução no 13 , do 
Conselho de Gestão de Previdência Complementar (CGPC), que essas entidades passaram a também adequar suas ações administrativas e de controles às práticas, princípios e regras de governança corporativa.

As Entidades Fechadas de Previdência Complementar, também conhecidas como Fundos de Pensão, na definição de Silva (2007), são aquelas criadas por empresas, ou grupos de empresas, denominadas patrocinadoras, oferecendo por meio de adesão planos de benefícios previdenciários aos seus empregados.

Por administrar recursos de terceiros, a adoção de práticas de governança corporativa nessas entidades, contribui para uma administração mais consistente, visto que a busca de padrões de segurança econômico-financeira e atuarial deverá ser uma constante, tanto por parte do conselho diretor das entidades, quanto pela suas próprias patrocinadoras.

Assim, a proposta de implantação de melhores práticas de gestão nas Entidades Fechadas de Previdência Complementar aliado ao Princípio da Transparência, leva ao seguinte questionamento: De que forma as práticas de governança corporativa estão sendo divulgadas nos endereços eletrônicos das Entidades Fechadas de Previdência Complementar?

A resposta a este questionamento contribuirá para conhecer a forma como se estabelece a comunicação com participantes e assistidos sobre as ações de segurança econômico-financeira e atuarial dos planos de benefícios.

Da recente produção científica brasileira pesquisada acerca do tema governança corporativa nas EFPC's destacam-se os estudos de sobre a gestão dos ativos nessas entidades na aplicação dos recursos em empresas que praticam governança corporativa e que negociam suas ações na Bolsa de Valores do Estado de São Paulo (BELCHER, 2004; RIECHE, 2005; PUNSUVO et. al., 2007). Assim como pesquisas sobre o papel dos investidores institucionais para adoção de práticas de governança corporativas nas empresas e a preocupação com os controles internos e a transparência nas informações (THOMPSON-FLORÊS, 2004; SOUZA, 2008)

Não foram identificadas, entretanto, pesquisas empíricas que tratam da governança corporativa nas EFPC's sob o aspecto da divulgação de informações para os participantes, assistidos e sociedade em relação às atividades desenvolvidas pela gestão. Assim, o objetivo dessa pesquisa é evidenciar a divulgação de informações das práticas de governança corporativa nos endereços eletrônicos das Entidades Fechadas de Previdência Complementar.

Outro aspecto reforça a justificativa desta pesquisa: os cenários construídos por especialistas têm apontado para um crescimento do segmento fechado de previdência complementar. $\mathrm{O}$ capital dessas entidades durante a última década tem apresentado um crescimento significativo e ainda apresenta tendência de crescimento para os próximos anos, particularmente em função das mudanças 
demográficas e do padrão de reforma que vive o sistema previdenciário mundial. No mercado brasileiro percebe-se a interiorização das EFPC's por todo o território nacional. (HU, 2006; CHAGAS, 2006)

Este estudo se restringirá a evidenciar os reflexos nas informações divulgadas aos participantes respaldadas pela adoção de práticas de governança corporativa nas Entidades Fechadas de Previdência Complementar nos sítios eletrônicos.

\section{Revisão da Literatura}

\subsection{Conceitos e Objetivos da Governança Corporativa}

A governança corporativa, na visão de Shleifer e Vishny (1986), lida com as formas pelas quais os financiadores de corporações asseguram-se do retorno de seu investimento, estabelecendo mecanismos de governança por meio de instituições econômicas e jurídicas sujeitas às alterações advindas do processo político.

Dentro de um contexto das atividades empresariais, Silva e Leal (2007) afirmam que, de maneira bem genérica, governança corporativa (governança empresarial) pode ser descrita como os mecanismos ou princípios que governam o processo decisório dentro de uma empresa.

No processo decisório os conflitos de agência - tanto os derivados do oportunismo de gestores face à dispersão e à ausência dos acionistas, quanto os associáveis a estruturas de propriedade acionária que ensejam a expropriação dos direitos de minoritários por ações oportunistas de majoritários - são minimizados com o conjunto de controles trazidos pela governança corporativa. (SILVEIRA, 2004; ANDRADE; ROSSETTI, 2007).

Sendo assim, o objetivo de aprimorar as relações entre as companhias e o mercado investidor faz da governança corporativa uma forma de estabelecer a sintonia entre as empresas e o mercado abrangendo também os fornecedores, consumidores e a coletividade em que atua a empresa.

Em um sentido mais amplo, a governança corporativa é definida por Garcia e Souza (2005):

...um sistema de normas de estruturação da sociedade anônima, por meio do qual se atribuem responsabilidades aos participantes da atividade empresarial, como o grupo de controle, o conselho de administração, a diretoria, o conselho fiscal, assegurando direitos aos acionistas minoritários, aos empregados, fornecedores, clientes e à comunidade em que a empresa atua, permitindo uma melhor identificação dos objetivos da empresa e dos meios de atingi-los e propiciando mais eficiente fiscalização do desempenho dos diversos órgãos da sociedade.

Percebe-se que o conceito de governança corporativa pode ser estendido 
a qualquer organização. Para Drucker (1995) a governança é constituída pelo conjunto dos mecanismos do poder de controle, que existem para fazer com que uma organização cumpra sua missão e atinja os objetivos estipulados pelos seus acionistas e demais participantes relevantes.

Nesse sentido, observa-se que o conceito de governança corporativa se traduz em sinônimo de boas práticas de gestão e de respeito e transparência no relacionamento das companhias com todos os seus acionistas e entidades do mercado de capitais, bem como com os clientes e a sociedade.

As boas práticas de governança corporativa tratam do conjunto de leis e regulamentos que visam: a) assegurar os direitos dos acionistas das empresas, controladores ou minoritários; b) disponibilizar informações que permitam aos acionistas acompanhar decisões empresariais impactantes, avaliando o quanto elas interferem em seus direitos; c) possibilitar diferentes públicos alcançados pelos atos da empresas o emprego de instrumentos que assegurem a observância de seus direitos; d) promover interação dos acionistas, dos conselhos de administração e da direção executiva das empresas; e) aumentar a transparência e melhorar a imagem institucional; f) agregar valor à entidade e contribuir para a sua perenidade. (MONKS; MINOW, 2004; RODRIGUEZ; SEGRETTI, 2005; ANDRADE; ROSSETTI, 2007)

Especialistas dos mercados de capitais nacionais e internacionais defendem como princípios fundamentais da boa governança corporativa: transparência (disclosure), prestação de contas (accountability), eqüidade (fairness), cumprimento das leis (compliance).

Andrade e Rossetti (2007) definem disclosure como transparência das informações, especialmente de alta relevância, que impactam os negócios e que envolvem resultados, oportunidades e riscos.

Para Lodi (2000) accountability é a responsabilidade pela prestação de contas por parte daqueles que tomam as decisões de negócios, fundamentada nas melhores práticas de contabilidade e de auditoria.

Fairness segundo Andrade e Rossetti (2007), é o senso de justiça, eqüidade no tratamento dos acionistas. Respeito aos direitos dos minoritários, por participação equânime com a dos majoritários, tanto no aumento da riqueza corporativa, quanto nos resultados das operações, quanto ainda na perspectiva em assembléias gerais.

O papel da compliance na organização, de acordo com Silva (2006), é assessorar o gerenciamento do negócio no que se refere à interpretação e impacto da legislação, monitorando as melhores práticas em sua execução.

Mais recentemente, o Código das Melhores Práticas de Governança Corporativa, elaborado pelo IBGC, inclui também como princípio básico a responsabilidade corporativa, o equilíbrio entre os desempenhos econômico-financeiro, 
ambiental e social.

\subsection{A Governança nas Entidades Fechadas de Previdência Privada}

A previdência social brasileira compõe-se de dois núcleos fundamentais: o básico que tem natureza estatal e pública e o complementar que tem caráter particular privado. De acordo com dicionaristas pátrios, entende-se como complementar aquele que serve de complemento; adicional.

Além da aposentadoria básica conhecida mais popularmente como INSS, alguns trabalhadores recebem suplementação de aposentadoria. Essa suplementação pode ser considera como uma técnica de proteção destinada a proporcionar rendas ou pecúlios paralelos, não necessariamente acrescidos ao sistema oficial, através da adição ou não do desembolsado pela autarquia federal (INSS), com valores juridicamente dependentes ou não deste último. Verdadeiramente complementar, quando aumenta o benéfico básico. (MARTINEZ, 2002)

A suplementação ou complementação de aposentadoria é concebida através de entes privados e denominada de Previdência Privada. No Brasil a Previdência Privada foi oficialmente regulamentada na década de 70 pela Lei $n^{\circ}$. 6.435/77, e separada em dois segmentos denominados: Entidades Fechadas e Entidades Abertas. A primeira é também conhecida por Fundos de Pensão, interesse dessa pesquisa, que são constituídas no âmbito das empresas, exclusivamente na forma de entidades sem fins lucrativos e tem como característica básica a obrigatoriedade da contribuição do empregador, podendo o empregado contribuir ou não. A segunda, Entidades Abertas, podem ser constituídas nas formas de entidades sem fins lucrativos (muito comum antes do advento da Lei - os chamados "Montepios") e entidades com finalidade lucrativa, ligadas geralmente ao mercado financeiro, tendo bancos e seguradoras como acionistas majoritários.

As práticas de controles internos e a necessidade de clareza e transparência nas demonstrações contábeis dos fundos de pensão são justificadas em virtude de que as principais fontes de recursos dessas entidades estão baseadas não no mercado organizado, mas nos conceitos de cidadania responsabilidade social, nem sempre constantes e previsíveis, que de acordo com Araújo (2005) determina a necessidade de se encontrarem formas de gerenciamento que as façam manter seus serviços e, assim, garantir a continuidade.

Com vistas a encontrar formas de gerenciamento adequado para garantir a continuidade dessas entidades e a segurança dos planos de benefícios, a Secretaria de Previdência Complementar (SPC) criou em $1^{\circ}$ de outubro de 2004, a Resolução CGPC $n^{0} 13$, estabelecendo uma série de exigências no âmbito da gestão e dos controles internos das entidades, apontando a emergência de um novo padrão de governança global para os fundos de pensão. Para tal, a entidade deve adotar prin- 
cípios, regras e práticas de governança, gestão e controles internos adequados ao porte, complexidade e riscos. É recomendável, também, o manual de Governança Corporativa (artigo $1^{\circ}$ e $\S 2$ ) e o Código de Ética (artigo $1^{\circ}$ e $\S$ Único).

Para cumprir com o princípio da transparência na gestão das Entidades Fechadas de Previdência Complementar, em 06 de dezembro de 2006, houve a publicação da Resolução (CGPC) nº. 23, a qual dispõe sobre os procedimentos a serem observados por essas na divulgação de informações aos participantes e assistidos dos planos de benefícios que administram. Por essa legislação, os demonstrativos contábeis estabelecidos na Resolução CGPC nº 05 de 30 de janeiro de 2002 são ratificados, e os relatórios anuais de informações a participantes e assistidos são aprimorados com a inclusão de informações relativas à política de investimentos, o demonstrativo de investimentos e alterações de Estatuto ou Regulamento dos planos, tornando obrigatória a disponibilização de informações por meio eletrônico.

Todos esses normativos visam, principalmente, determinar padrões mínimos de segurança econômico-financeira e atuarial, com fins específicos de preservar a liquidez, a solvência e o equilíbrio dos planos de benefício, isoladamente e no conjunto de suas atividades, de maneira a preservar o patrimônio dos participantes e assistidos. Além disso, procura-se dar aos participantes pleno acesso às informações relativas à gestão de seus respectivos planos de benefício, que deverá ser o mais transparente possível, bem como impor severas sanções aos gestores pelo não cumprimento da lei.

O cumprimento das normas legais, entretanto não garantem, por si só, que as informações divulgadas são o reflexo de uma gestão qualitativa. Como qualquer empresa, as EFPC's necessitam de controles eficazes, com uma visão integradora entre suas áreas, favorecendo a visualização da real situação patrimonial e dos resultados dos planos de benefícios, de modo a garantir a elaboração de análises objetivas e controle permanente do seu desempenho com a precisão e a transparência necessárias às tomadas de decisão. (OLIVEIRA; PONTE, 2005)

A idéia da necessidade de um sistema de informações qualitativas é reforçada por Souza (2008), que afirma que os fundos de pensão, independente do seu porte e tamanho, devem avaliar corretamente os riscos, mediante utilização de mecanismos adequados, segundo as melhores técnicas de gestão, com o objetivo de proteger os seus patrimônios e dar maior transparência.

\subsection{Controles Internos nas Entidades Fechadas de Previdência Privada}

Controle interno é um sistema que pode ser definido como processo de responsabilidade da direção da entidade desenhado para proporcionar razoável segurança e, assim, garantir a efetividade e eficiência das operações decorrentes 
da própria criação da entidade, incluindo o desempenho, a rentabilidade e a salvaguarda do patrimônio.

Estudos divulgados pelo COSO mostram a existência de dois modelos: o modelo mais antigo (1992) refere-se ao modo tradicional que não considera a cultura das empresas, enquanto o modelo denominado COSO-ERM (2004) procura identificar o elemento chave que influencia os riscos de práticas inadequadas e, para isso, efetuou diversas melhorias, como por exemplo:

a) Definiu um marco concreto para avaliar o controle interno a partir da perspectiva dos controles relacionados com os recursos humanos;

b) Enfatiza a necessidade de vincular os objetivos com a avaliação de riscos e estes com os controles;

c) Enfatiza o monitoramento conforme determina a Lei SarbanesOxley

d) Trata da transversalidade do componente de informação e comunicação que corresponde à qualidade da informação com o objetivo de perpassar todas as áreas e, em conseqüência, permitir uma visão apropriada para mitigar o risco de ocorrência de fraudes.

O modelo de controle do COSO está voltado para aspectos relevantes da governança corporativa quando divide os objetivos do controle interno em três categorias:

(a) Operacionais, que são orientados para o êxito dos resultados do negócio;

(b) De relatórios financeiros, os relativos à veracidade e fidedignidade das demonstrações contábeis.

(c) De cumprimento, são os que estabelecem a necessidade de cumprimento legal, de da legislação pertinente, dos regulamentos da atividade e das leis tributárias.

Para as Entidades Fechadas de Previdência Complementar as formas de implantação dos controles internos foram traçados em um modelo de gestão coerente, que permite o adequado gerenciamento dos riscos, as regras foram estabelecidas pelo órgão fiscalizador através da Resolução CGPC nº 13/04 que introduziu o conceito de governança corporativa nessas entidades.

Os gestores ao seguirem os princípios e regras ditadas pelas normas do Conselho de Gestão da Previdência Complementar poderão garantir uma boa gestão dos recursos nas entidades, baseada em atenuar os riscos que envolvem seu negócio, aliada a boa prática de governança corporativa e com liberdade de criar e desenvolver controles internos de acordo com as necessidades, porte e grau de complexidade de cada entidade.

Os controles internos permitem diagnosticar os riscos e vulnerabilidades de cada uma das áreas de atividades que as EFPC's estão expostas, bem como a elaboração de um conjunto de ações que deverão ser adotadas com o propósito de 
permitir uma melhor gestão dos riscos inerentes às atividades, a fim de garantir a segurança da situação econômico-financeiro e atuarial dos planos de benefícios. (SILVA, 2005)

Ainda em relação aos controles internos, Figueiredo e Caggiano (2006) afirmam que numa definição estreita, controle é associado geralmente com manutenção de padrões e imposição de penalidades. O conceito amplo de controle, encontrado na literatura da ciência da administração, trata o termo controle como sinônimo da própria administração.

Para reforçar a idéia de controle como administração, Crepaldi (2004), afirma que são todos os instrumentos da organização destinados à vigilância, fiscalização e verificação administrativa, que permitam prever, observar, dirigir ou governar os acontecimentos, que se verificam dentro da empresa e que produzam reflexos em seu patrimônio.

O controle como administração também está presente nas atividades desenvolvidas pelas Entidades Fechadas de Previdência Complementar através de pensamentos e práticas envolvendo o melhor da governança corporativa, ao lado de controles internos muito mais apurados. (SILVA, 2006),

A afirmativa de que os controles estão mais presentes nas atividades desenvolvidas pelas EFPC's é confirmada através da estrutura da Resolução CGPC n ${ }^{\circ} 13 / 04$ que está embasada nos chamados focos de controle, conforme demonstrado na Figura 1.

Figura 1 - Focos de Controle da Resolução CGPC n 13

\begin{tabular}{|l|l|}
\hline TÓPICO & ARTIGO \\
\hline Governança Corporativa & $1^{\circ} \mathrm{E} \S 1$ \\
Desenvolvimento de Cultura Interna & $2^{\circ}$ \\
Postura Ética & $3^{\circ}$ \\
Competência Técnica e Experiência Profissional & $4^{\circ}$ \\
\hline Atribuições e Mandatos & $5^{\circ}$ \\
\hline Regimento Interno & $5^{\circ}$ e inciso III \\
\hline Estrutura Organizacional & $7^{\circ}$ \\
\hline Aderência da Política de Investimentos & $8^{\circ}$ \\
\hline Estrutura de Controles e Atendimento de Objetivos & $9^{\circ}$ \\
\hline
\end{tabular}

Fonte: Lopes (2005)

2.4 Responsabilidade dos Dirigentes e Conselheiros no Processo de Transparência da Gestão.

Com a mudança nas práticas de gestão, trazida pelos conceitos de governança corporativa, a responsabilidade dos administradores e conselheiros têm crescido cada vez mais. Verifica-se que a Resolução CGPC n ${ }^{\circ}$. 13/04 traz a exigência de que os gestores tenham competência técnica e gerencial compatível 
com a exigência legal e estatutária e com a complexidade das funções exercidas em todos os níveis da administração.

Quando o gestor deixa de observar as regras, os princípios e as práticas recomendadas e exigidas, não só pela Resolução mencionada, mas pelo conjunto da legislação aplicável à previdência complementar fechada, ele está agindo com abuso ou desvio de poder, podendo ser responsabilizado por isso administrativa, civil e penalmente. (PAGLIARINI, 2006)

Após a Resolução CGPC n $13 / 04$ e adequação das práticas de governança corporativa as responsabilidades dos dirigentes das Entidades Fechadas de Previdência Complementar foram ampliadas. Na realidade os órgãos diretivos passaram a ter os seguintes papéis: o Conselho Deliberativo é o responsável pela aprovação da política de controles internos, a Diretoria Executiva fica responsável pela elaboração e implantação e acompanhamento da política de controles internos, após aprovação do Conselho Deliberativo e o Conselho Fiscal passa a ser o responsável pela a avaliação da eficiência dos controles internos. (SILVA, 2006)

No ambiente de governança corporativa, quando estruturado os códigos de melhores práticas, o Conselho de Administração é o órgão guardião dos interesses dos proprietários. E é a Diretoria Executiva a responsável pelas ações que movimentarão a corporação, na implementação desses propósitos. (ANDRADE; ROSSETTI, 2007)

Ainda nesse ambiente de governança Esculder e Tinoco (2008) expõem que o papel do conselho fiscal situa-se além daquelas simples atribuições previstas na legislação, mas, sobretudo, naquelas em que estão subentendidas, como: controle e acompanhamento dos controles internos, planejamento estratégico e orçamentário já que faz parte do sistema de controle e fiscalização.

Outro aspecto a ser considerado é que os recursos existentes numa Entidade Fechada de Previdência Complementar pertencem aos participantes do plano, e estes delegam aos dirigentes a tomada de decisão quanto à rentabilização destes recursos para a sua aposentadoria, percebe-se que a necessidade de transparência nas ações da gestão fica ainda mais evidente.

De acordo com Souza (2008), a transparência é imprescindível desde o aspecto do ajuste negocial até a gestão dos recursos envolvidos. O participante deve ter amplo e total conhecimento do sistema e de suas próprias reservas.

\subsection{A Divulgação de Informações para os Participantes, Assistidos e a Socie- dade.}

Em um regime de contribuição e proteção que tenha como objetivo constituir uma reserva para garantir o futuro, a exemplo do FGTS e da poupança individual, é absolutamente necessário o participante ter conhecimento, não só 
das provisões como de todo o sistema, as contas da entidade gestora, sua organização, como é gerenciado e por quem, além de tomar ciência do destino e risco das aplicações. (STEPHANES, 1999)

Essa necessidade de ciência da gestão dos recursos é reafirmada por Klapper e Love (2004), em seus estudos observaram que quanto maior a transparência, maior o valor da firma. Em consonância com essa idéia, Silva e Leal (2007), evidenciam que existe a hipótese de que firmas que divulgam seus relatórios financeiros dentro do prazo legal e que usam padrões internacionais de contabilidade e auditores com reputação global são consideradas como possuindo boas praticas de governança corporativa.

Neste sentido, além dos relatórios financeiros, no caso das Entidades Fechadas de Previdência Complementar, outras informações podem ser divulgadas sobre as ações dos dirigentes nas empresas. Os participantes ativos e inativos podem requisitar informações sobre: suas situações individuais junto à entidade, a saúde financeira e atuarial do plano, os custos incorridos e os objetivos da EFPC.

Corroborando com esse entendimento, Souza (2008) defende que a transparência da situação econômico-financeira e atuarial dos fundos de pensão para participantes, patrocinadoras, Ministério Público, órgãos do governo Federal e a sociedade civil só vem a incentivar um maior número de adesões, pois demonstra concretamente o aspecto da confiabilidade do sistema.

Em relação à confiabilidade do sistema outro aspecto a ser considerado é o risco de imagem da instituição junto a clientes, concorrentes, órgãos reguladores, parceiros comerciais etc. Na visão de Pagliarini (2006), este risco decorre da publicidade negativa de informações e é minimizado com a adoção de normas de transparência da gestão da entidade e dos planos por ela operados. Para as Entidades Fechadas de Previdência Complementar o risco de imagem está diretamente associado ao Principio da Transparência que norteia todas as ações realizadas na entidade.

A respeito do Princípio da Transparência, Felix (2009), firma que a necessidade de integração por meio do processo comunicativo entre os vários atores de um sistema de informação deve estar estruturada de forma que haja facilidade de entendimento na transmissão de informação, confiabilidade e clareza.

Em resumo, percebe-se que a comunicação com os participantes, patrocinadores e/ou instituidores e órgãos fiscalizadores, através de divulgações constantes de informações, além das já estabelecidas em normativos, cria um vinculo de confiabilidade e clareza nos planos da entidade e nas atividades realizadas pela gestão em contrapartida a diminuição do risco. Desta forma, um sistema eficiente de comunicação que permita ao participante o completo acompanhamento de seus interesses é tão necessário quanto uma política de investimentos. 


\section{Proceder Metodológico}

\subsection{Amostra, Coleta e Tratamento dos Dados}

Foi utilizada uma amostra por conveniência, não-probabilística. Segundo Beuren (2006), nessa técnica de amostragem, fazem uso do raciocínio, dependendo exclusivamente dos critérios do pesquisador para construir as amostras.

Dentro do universo quantitativo das EFPC's, de acordo com a Associação Brasileira das Entidades Fechadas de Previdência Complementar, atualmente no país, existem 369 Entidades sendo 81 Públicos e 288 Privados. Para a realização deste estudo, foram pesquisadas as 50 maiores entidades em termos de ativos de investimentos de acordo com o ranking da revista Fundos de Pensão, número 350, de março de 2009, publicada pela ABRAPP/SINDAPP/ICSS.

A escolha da amostra justifica-se pela relevância que as 50 maiores entidades (em termos de ativo) possuem em relação à quantidade de participantes, assistidos e à abrangência da divulgação das informações a um maior contingente populacional.

Para confirmar esta relação foi efetuado um comparativo entre as estimativas totais para as Entidades Fechadas de Previdência Complementar, apresentados pela ABRAPP e os números apresentados na amostra escolhida, verificando-se a representatividade da amostra em relação ao total de Ativos em Investimentos, de Participantes Ativos, de Dependentes e de Assistidos, conforme demonstrado na Figura 2.

Figura 2 - Representatividade da Amostra em Relação à Estimativa Total para os Fundos de Pensão

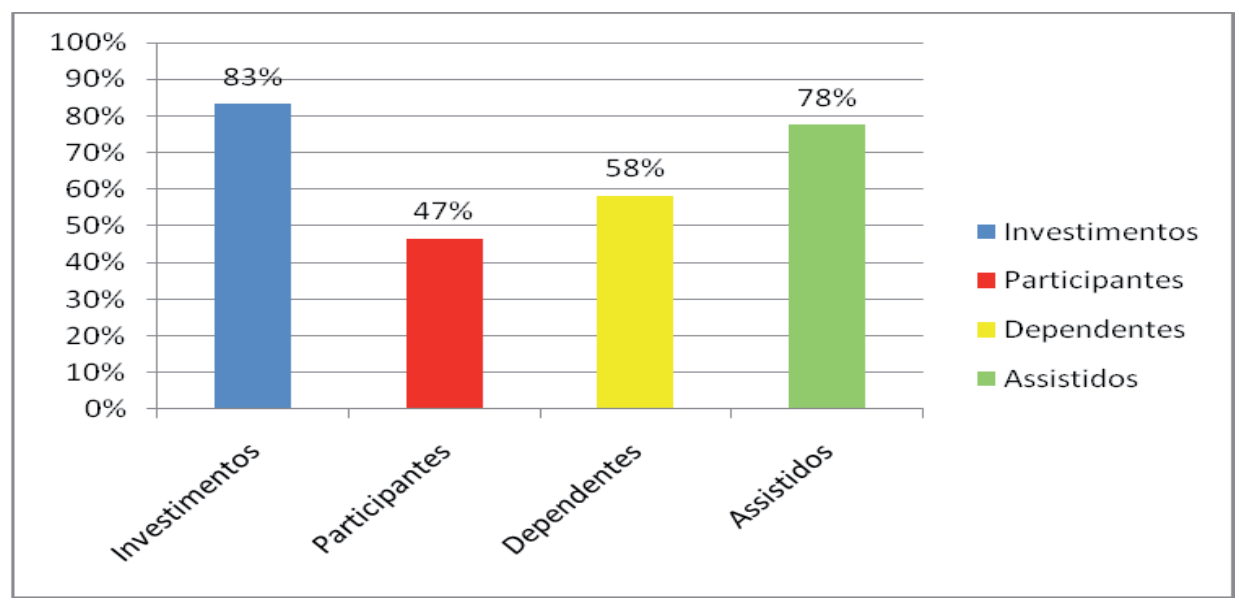

Fonte: Dados da Pesquisa

Foi aplicado um formulário padronizado em forma de check-list contendo os principais pontos a serem observados pelas Entidades Fechadas de Previdência Complementar na adequação às práticas de governança corporativa e de transparência de suas informações aos usuários. $\mathrm{O}$ formulário foi respondido mediante 
observação direta investigativa do autor em sua visita à página eletrônica das empresas.

A observação investigativa para o preenchimento dos formulários desta pesquisa ocorreu entre os dias 31 de maio e 2 de junho de 2009. Da amostra inicial de 50 entidades, foram investigadas nesta pesquisa 46 entidades, não sendo possível o acesso eletrônico dos website das 4 entidades restantes, por estarem "fora do ar" ou por não apresentarem endereço eletrônico de acesso.

O tratamento estatístico utilizado foi a análise descritiva dos dados obtidos na pesquisa, com base na utilização de medida de posição e dispersão, e teste nãoparamétrico Exato de Fischer, calculados com o auxílio do software estatístico SPSS na versão 15. O teste não paramétrico foi escolhido por ser útil na análise de dados provenientes de pesquisas na área de ciências do comportamento e por ser o mais indicado nos estudos que envolvem variáveis de mensuração nominal e ordinal, que corresponde à maioria das variáveis estudadas neste trabalho. Provas não paramétricas são também denominadas provas de livre distribuição de probabilidade da população. (Martins, 2005)

\subsection{Formulário Padronizado para coleta de dados}

Para atender aos objetivos do presente estudo, buscou-se analisar a divulgação de informações relacionadas ao tema Governança Corporativa nas Entidades Fechadas de Previdência Complementar para pessoas com acesso a internet, como sendo este um meio de comunicação capaz de abranger um grande número interessados, não só no país como também no exterior.

Na elaboração das questões contidas no formulário da pesquisa utilizou-se como referencial: o Código das Melhores Práticas do IBGC; a Resolução CGPC $n^{\circ}$ 13/2004 e a Resolução CGPS nº 23/2006. O formulário apresenta 25 perguntas divididas em grupos: Identificação; Acesso a Informação; Conteúdo das Informações Publicadas; Estrutura da Gestão; Estrutura de Propriedade e Controle; e Outras Informações. Conforme apresentado na Figura 3. 
Figura 3 - Check-List das Informações Divulgadas nos Websites

\begin{tabular}{|c|c|}
\hline $\begin{array}{l}\text { Identificação da } \\
\text { Entidade }\end{array}$ & Sigla, Sítio, Ano de Fundação, Sede, Quantidade de Planos, Quantidade de Patrocínios \\
\hline \multirow{5}{*}{ Acesso a Informação } & $\begin{array}{l}\text { É possível obter o Relatório Anual (RA) de acordo com as determinações da Resolução } \\
\text { 23/2006 na internet? }\end{array}$ \\
\hline & O website dispõe de documentos relativos à governança corporativa? \\
\hline & O website possui informações sobre as premissas e hipóteses atuariais? \\
\hline & Quantos "clicks" são necessários para acesso as informações no website? \\
\hline & $\begin{array}{l}\text { O website apresenta organograma da gestão e atas de reuniões com as deliberações do } \\
\text { Conselho Deliberativo? }\end{array}$ \\
\hline \multirow{5}{*}{$\begin{array}{l}\text { Conteúdo das } \\
\text { Informações } \\
\text { Publicadas }\end{array}$} & $\begin{array}{l}\text { O RA inclui uma seção específica dedicada à implementação de Princípios de } \\
\text { Governança Corporativa? }\end{array}$ \\
\hline & O website apresenta Código de Ética e de conduta? \\
\hline & O website disponibiliza Estatuto e Regulamento dos planos? \\
\hline & O website divulga relatório de monitoramento de riscos? \\
\hline & O website divulga relatório semestral do conselho fiscal? \\
\hline \multirow{5}{*}{ Estrutura da Gestão } & $\begin{array}{l}\text { Os Cargos de Diretor Executivo e Presidente do Conselho Deliberativo são ocupados por } \\
\text { pessoas diferentes? }\end{array}$ \\
\hline & O website apresenta composição da Diretoria? (Quantidade) \\
\hline & O website apresenta composição do Conselho Deliberativo? (Quantidade) \\
\hline & O website apresenta composição do Conselho Fiscal? (Quantidade) \\
\hline & O website apresenta currículos dos dirigente e conselheiros? \\
\hline \multirow{5}{*}{$\begin{array}{l}\text { Estrutura de } \\
\text { Propriedade e } \\
\text { Controle }\end{array}$} & O website demonstra as operações com partes relacionadas \\
\hline & O website possui um cadastro com pessoas politicamente expostas? \\
\hline & O website proporciona formulário para atualização de informações cadastrais? \\
\hline & O website disponibiliza informações individuais sobre o plano específico do usuário? \\
\hline & $\begin{array}{l}\text { O website possui ouvidoria ou outra forma de contato com online com o Fundo de } \\
\text { Pensão? }\end{array}$ \\
\hline Outras Informações & Que outras informações ambientais e sociais são disponibilizadas no website? \\
\hline
\end{tabular}

Fonte: Dados da Pesquisa

\subsection{Análise dos Resultados}

Na identificação das entidades participantes da pesquisa observou-se que $63 \%$ têm sua sede localizada na Região Sudeste e no Distrito Federal, demonstrando a proximidade geográfica com grandes centros financeiros do País. Com relação ao tempo de existência, 74\% tiveram sua criação anterior a 1980, destacando-se a PREVI, entidade mais antiga, com 105 anos de fundação, como mostra a tabela 1 - Tempo de Fundação. Essa informação revela a solidez e a consolidação dessas entidades dentro do mercado brasileiro, bem como a maturidade em termos de estrutura de funcionamento.

\section{Tabela 1 - Tempo de Fundação}

\begin{tabular}{c|cc|c}
\hline Tempo & Freqüência & Percentual & $\begin{array}{c}\text { Percentual } \\
\text { Acumulado }\end{array}$ \\
\hline $1904-1969$ & 6 & $13 \%$ & $13 \%$ \\
$1970-1979$ & 28 & $61 \%$ & $74 \%$ \\
$1980-1989$ & 6 & $13 \%$ & $87 \%$ \\
$1990-2004$ & 4 & $9 \%$ & $96 \%$ \\
Não In forma & 2 & $4 \%$ & $100 \%$ \\
Total & 46 & $100 \%$ & \\
\hline
\end{tabular}

Fonte: Dados da Pesquisa 
Sobre o acesso a informações, a Resolução GCPC no 23/2006 tornou obrigatória, para as Entidades Fechadas de Previdência Complementar, a elaboração do Relatório Anual de Informações contendo no mínimo o demonstrativo patrimonial e de resultados por plano de benefícios, informações referente à política de investimentos, relatório resumo das informações sobre demonstrativo de investimentos, parecer atuarial dos planos de benefícios, informações segregadas sobre as despesas do plano de benefício, além de informações sobre alterações de estatuto e regulamento, quando houver.

Dessa forma, o Relatório Anual deve ser encaminhado por meio impresso aos participantes e assistidos, porém sua divulgação poderá ocorrer também em meio eletrônico. Dentro da amostra selecionada $73,9 \%$ das entidades evidenciam no website o Relatório Anual de acordo com a normativa legal, 10,9\% apresentam apenas de maneira parcial e as demais apresentam demonstrações contábeis, política de investimentos e outras informações de maneira isolada não se configurando como relatório, conforme apresentado na tabela 2 - Relatório Anual de Acordo com a Norma Legal.

Tabela 2 - Relatório Anual de Acordo com a Norma Legal

\begin{tabular}{c|c|c|c}
\hline Relatório Anual & Freqüência & Percentual & $\begin{array}{c}\text { Percentual } \\
\text { Acumulado }\end{array}$ \\
\hline Não & 3 & 6,5 & 6,5 \\
Sim & 34 & 73,9 & 80,4 \\
Parcialmente & 5 & 10,9 & 91,3 \\
Não Evidência & 4 & 8,7 & 100,00 \\
Total & 46 & 100,00 & \\
\hline
\end{tabular}

Fonte: Dados da Pesquisa

Outro aspecto analisado em relação ao acesso às informações é que a Resolução CGPC n ${ }^{\circ}$. 13/04 introduziu o conceito de governança corporativa nas Entidades Fechadas de Previdência Complementar, entretanto apenas 19 entidades possuem uma seção específica sobre assunto onde, de maneira geral, é apresentado o manual de governança corporativa, como demonstrado na tabela 3.

Tabela 3 - Seção Específica da Governança Corporativa

\begin{tabular}{c|c|c|c}
\hline $\begin{array}{c}\text { Seção de } \\
\text { Governança }\end{array}$ & Freqüência & Percentual & $\begin{array}{c}\text { Percentual } \\
\text { Acumulado }\end{array}$ \\
\hline Não & 27 & 58,7 & 58,7 \\
Sim & 19 & 41,3 & 100,00 \\
Total & 46 & 100,00 & \\
\hline
\end{tabular}

Fonte: Dados da Pesquisa

Procurou-se identificar a existência de relação entre o tamanho da entidade e a existência de seção específica sobre Governança Corporativa, conforme 
demonstrado na tabela 4.

Tabela 4 - Tamanho por Ativos de Investimentos versus Apresentação de Seção sobre Governança Corporativa

\begin{tabular}{c|c|c|c|c|c}
\hline \multirow{2}{*}{ Variável explicativa } & \multicolumn{3}{c|}{$\begin{array}{c}\text { Apresenta seção de } \\
\text { governança }\end{array}$} & \multirow{2}{*}{$\begin{array}{c}\text { Exato de Fisher } \\
\text { Sig. }(\alpha)\end{array}$} \\
\cline { 3 - 5 } \multicolumn{2}{c|}{} & Não & Sim & Total & \\
\hline Tamanho por ativo & As 10 maiores & 2 & 8 & 10 & 0 \\
de investimentos & As 10 menores & 7 & 1 & 8 & 0,008 \\
& Total & 9 & 9 & 18 & \\
\hline
\end{tabular}

Fonte: Dados da Pesquisa

Entre as 10 menores entidade, em 2 não foi possível obter acesso ao endereço eletrônico, justificado o total de 18 entidades. Através do teste exato de Fisher, com grau de significância de $0,8 \%$, verificou-se que as maiores Entidade Fechadas de Previdência Complementar em termos de ativos de investimentos têm uma maior preocupação em divulgar informações sobre governança corporativa através de seção específica no website.

Esta pesquisa testou a possibilidade de relação entre as entidades que evidenciam o Relatório Anual de acordo com a Resolução no 23/2006 com aquelas que apresentam seção específica sobre governança corporativa, conforme demonstrado na tabela 5 .

Tabela 5 - Relatório Anual de Acordo com Normativo versus Apresentação de Seção sobre Governança Corporativa

\begin{tabular}{c|c|c|c|c|c}
\hline \multirow{2}{*}{\begin{tabular}{l} 
Variável explicativa \\
\multicolumn{2}{l|}{}
\end{tabular}} & \multicolumn{3}{|c|}{$\begin{array}{c}\text { Apresenta seção de } \\
\text { governança }\end{array}$} & \multirow{2}{*}{$\begin{array}{c}\text { Exato de Fisher } \\
\text { Sig. }(\alpha)\end{array}$} \\
\cline { 3 - 5 } & Não & Sim & Total & \\
\hline Relatório anual de & Não & 8 & 4 & 12 & \\
acordo com a & Sim & 19 & 15 & 34 & 0,382 \\
norma legal & Total & 27 & 19 & 46 & \\
\hline
\end{tabular}

O teste exato de Fisher apresentou grau de significância maior que 5\% demonstrando que não existe relação entre essas variáveis, percebe-se então, que a obrigatoriedade de elaboração de Relatório Anual não está diretamente relacionada com a preocupação de algumas entidades em apresentar informações sobre a forma de atuação da gestão.

Ainda no contexto do acesso a informações, a Resolução CGPC n ${ }^{0}$ 13/2004 estabelece que a comunicação com os participantes e assistidos deve ser feita em linguagem clara e acessível, reafirmando o princípio da transparência que norteia as ações ocorridas nos fundos de pensão. Esta pesquisa testou o grau de dificuldade de acesso às informações contidas nos Relatórios Anuais, através da quantidade de cliques necessários para se chegar a essas informações, conforme demonstrado na tabela 6 .

Conforme testado, em $80,4 \%$ das páginas eletrônicas o acesso às infor- 
mações é rápido e fácil sendo necessário no máximo 3 cliques, em apenas 5 entidades o acesso é restrito aos usuários cadastrados ou não apresenta Relatório Anual. Foi também verificado a linguagem utilizada na comunicação, em geral, são palavras simples de uso comum, por exemplo: relatório anual (ano), relatório da administração, relatório de atividades, informações para você, informações financeiras, dentre outras.

Tabela 6 - Grau de Dificuldade para Acesso ao Relatório Anual
\begin{tabular}{c|c|c|c}
\hline $\begin{array}{c}\text { Quantidade de } \\
\text { cliques }\end{array}$ & Frequência & Percentual & $\begin{array}{c}\text { Percentual } \\
\text { Acumulado }\end{array}$ \\
\hline apenas 1 & 16 & 34,8 & 34,8 \\
até 2 & 11 & 23,9 & 58,7 \\
até 3 & 10 & 21,7 & 80,4 \\
acima de 4 & 4 & 8,7 & 89,1 \\
não apresenta/restrito & 5 & 10,9 & 100 \\
total & 46 & 100 & 100 \\
\hline
\end{tabular}

Fonte: Dados da Pesquisa

$\mathrm{Na}$ análise do conteúdo das informações disponibilizadas, $67,4 \%$ das entidades não apresentam item com título específico governança corporativa dentro do Relatório Anual. Na página eletrônica a maioria das entidades disponibiliza Código de Ética, Estatuto, Regulamento dos Planos, entretanto $76 \%$ não apresentam relatório de monitoramento de riscos dos investimentos e apenas 4 entidades divulgam o relatório semestral do Conselho Fiscal de acompanhamento das ações econômico-financeiras e de controles internos das entidades.

A análise da Estrutura da Gestão está relacionada com a composição e o funcionamento do conselho e dirigentes. Para Silva e Leal (2007) o tamanho do conselho é um importante mecanismo de controle, pois uma das tarefas do conselho é monitorar e disciplinar a administração executiva da companhia. Nesta pesquisa foi verificado que $87 \%$ das entidades evidenciam no sítio eletrônico a composição dos Conselhos Deliberativo e Fiscal. Em 45,7\% dos fundos de pensão o Conselho Deliberativo é composto por 6 membros e em 56,5\% o Conselho Fiscal é composto por 3 ou 4 membros.

Também foi analisado se os Diretores Executivos e os presidentes dos conselhos são as mesmas pessoas, nos estudos apresentados por Silva e Leal (2007) as firmas com essas características possuem valores de mercado menores. De acordo com melhores práticas de governança corporativa recomendadas pelo IBGC os presidentes não deverão acumular funções. Das entidades que evidenciam a composição da diretoria e dos conselhos em $87 \%$ os cargos de presidente do conselho e diretor executivo são ocupados por pessoas diferentes.

Dentro, ainda da estrutura de gestão, está pesquisa procurou identificar a apresentação de currículo de dirigentes e conselheiros nos websites, pois o artigo $4^{\circ}$ 
da Resolução CGPC n ${ }^{\circ} 13$ determina como imprescindível a competência técnica e gerencial, compatível com a exigência legal e estatutária e com a complexidade das funções exercidas, em todos os níveis da administração da EFPC.

Tabela 7 - Apresentação de Currículo de Dirigentes e/ou Conselheiros versus Apresentação de Seção sobre Governança Corporativa

\begin{tabular}{c|c|c|c|c|c}
\hline \multirow{2}{*}{\multicolumn{2}{c|}{ Variável }} & \multicolumn{3}{|c|}{$\begin{array}{c}\text { Apresenta seção de } \\
\text { governança }\end{array}$} & \multirow{2}{*}{$\begin{array}{c}\text { Exato de Fisher } \\
\text { Sig. }(\alpha)\end{array}$} \\
\cline { 3 - 5 } & Não & Sim & Total & \\
\hline Apresenta currículo & Não & 27 & 13 & 40 & \\
de dirigentes e/ou & Sim & 0 & 6 & 6 & 0,003 \\
conselheiros & Total & 27 & 19 & 46 & \\
\hline
\end{tabular}

Fonte: Dados da Pesquisa

Como demonstrado na tabela 7, através do teste exato de Fisher, com grau de significância de $0,3 \%$, verificou-se que as entidades com preocupação em divulgar informações sobre governança corporativa através de seção específica na página eletrônica, têm maior preocupação em apresentar currículo dos dirigentes e/ou conselheiros.

$\mathrm{Na}$ estrutura de propriedade e controle as relações que se estabelecem entre propriedade e os gestores são basicamente determinadas pela estrutura da propriedade e pela categoria do controlador, e disso depende a eficácia do modelo de governança, os resultados de balanço e a avaliação das empresas pelo mercado. (ANDRADE; ROSSETTI, 2007)

No presente estudo buscou-se examinar a relação de estrutura de controle na evidenciação das informações divulgadas nas páginas eletrônicas, considerando os participantes e assistidos como "acionistas" interessados nas decisões de estrutura de capital, ou seja, a forma como os recursos do seu plano específico estão sendo geridos e os impactos na reserva de poupança.

$\mathrm{Na}$ análise da divulgação de informações relativas à estrutura de propriedade e controle, apenas 19,6\% das entidades apresentam algum tipo de relatório que demonstra as operações com partes relacionadas e as decisões dos representantes dessas entidades nas reuniões deliberativas.

Verificou-se também que $65,2 \%$ das entidades disponibilizam informações financeiras individuais por tipo de plano de benefícios, em três entidades, porém esse acesso é restrito aos usuários cadastrados. Essas informações aumentam o grau de transparência na estruturação do capital e na gestão de recursos dos participantes e assistidos.

Essa pesquisa observou, ainda, que $93,5 \%$ dos fundos de pensão possuem uma seção de ouvidoria, onde o participante pode esclarecer suas duvidas, fazer sugestões ou efetuar reclamações sobre a forma de gestão dos planos de bene- 
fícios. Denotando a preocupação das entidades com o tratamento equânime aos participantes e assistidos.

Na terceira versão do Código de Melhores Práticas de Governança Corporativa, de março de 2004, destacou-se a inclusão do princípio de responsabilidade corporativa evidenciando a importância de as ações serem integradas, considerando também o aspecto social e ambiental, e não só econômico.

Durante a observação investigativa aos websites das Entidades Fechadas de Previdência Complementar, foram identificadas diversas ações ambientais e sociais, como exemplo: balanço social, relatório social, dicas de preservação da saúde, educação financeira, gestão de qualidade, consciência ecológica, educação previdenciária e preparação para aposentadoria.

Dentro do contexto de divulgação de informações através dos endereços eletrônicos dos fundos de pensão, percebe-se que além das informações financeiras e das relacionadas à estrutura da gestão, existe a preocupação com informações sobre as políticas e práticas sociais, ambientais, de previdência e de saúde.

\section{Conclusão}

O princípio da transparência que norteia as ações das Entidades Fechadas de Previdência Complementar, por administrar recursos financeiros de terceiros, é também um dos pilares das boas práticas de governança corporativa, onde as corporações devem cultivar o desejo de informar a fim de gerar um clima de confiança tanto interno, quanto nas relações com terceiros.

Assim, as boas práticas de governança corporativa devem estar refletidas nas informações divulgadas aos participantes e assistidos das Entidades Fechadas de Previdência Complementar. O presente estudo teve como foco a observação dessas informações divulgadas através dos endereços eletrônicos dessas entidades.

Através da análise dos dados foi possível identificar que parte significativa das entidades pesquisadas tem preocupações em divulgar as informações contidas nos normativos infralegais. Já em relação itens não obrigatórios, porém que caracterizam a adoção de boas práticas de governança corporativa existe lacunas na divulgação das informações.

Outro ponto observado é a inexistência de padrões mínimos de divulgação de informações no website, assim foi possível identificar entidades que continham diversas informações e outras nas quais as informações eram bastante limitadas. Apesar de parte significativa apresentar linguagem simples e de fácil acesso aos usuários, a governança corporativa não está evidenciada de forma clara e na grande maioria nem mesmo existe seção específica sobre o assunto.

Verificou-se, ainda, a preocupação dessas entidades com a divulgação de 
políticas sócio ambientais, de educação previdenciária e de prevenção à saúde, demonstrando a consciência com a responsabilidade social.

Conclui-se que embora exista a obrigatoriedade de adoção de padrões mínimos de governança corporativa, essas práticas não estão sendo evidenciadas de forma clara aos participantes e assistidos que buscam as páginas eletrônicas como meio de informação sobre a gestão dos recursos dos planos em que participam.

Pela característica do processo de amostragem, essas conclusões são validas apenas para o conjunto de entidades observadas nessa pesquisa. No entanto, o número de empresas pesquisadas, sua representatividade e a forma criteriosa com que a pesquisa foi conduzida, permitem utilizar esses dados como indicativo de divulgação de informações sobre as práticas de governança corporativa na divulgação de informações das Entidades Fechadas de Previdência Complementar.

Para futuros trabalhos, recomenda-se que essa pesquisa seja replicada com uma amostra maior da população ou por regiões sede, para que se obtenha um quadro mais completo sobre as informações divulgadas dessas entidades nos endereços eletrônicos.

\section{Referências}

ANDRADE, Adriana. ROSSETTI, José Paschoal. Governança Corporativa: fundamentos, desenvolvimento e tendências. 3. ed. São Paulo: Atlas, 2007.

ARAÚJO, Osório Cavalcanti. Contabilidade para Organizações do Terceiro Setor. São Paulo: Atlas, 2005.

BELCHER, Flávia Coutinho de Moura Vallim. Gestão de Ativos de Fundos de Pensão: Práticas de Governança, Estrutura de Controle e Remuneração, 2004. Dissertação (Mestrado em Finanças e Economia Empresarial) - Curso de PósGraduação em Economia, Fundação Getulio Vargas, Rio de Janeiro, 2004.

BEUREN, Ilse Maria. Como Elaborar Trabalhos Monográficos em Contabilidade - Teoria e Prática. 3. Ed. São Paulo: Atlas, 2006

Brasil. Lei Complementar 109, de 29 maio de 2001. Dispõe sobre o Regime de Previdência Complementar e dá outras providências. Diário Oficial da União, 30 de maio de 2001.

Brasil. Resolução CGPC nº ${ }^{\circ}$ 13, de 01 de outubro de 2004. Estabelece princípios, regras e práticas de governança, gestão e controles internos a serem observados pelas entidades fechadas de previdência complementar - EFPC. Diário Oficial da União, 07 de dezembro de 2004. 
um estudo sobre a aderência da informação do passivo atuarial entre empresas patrocinadoras de plano de benefícios de aposentadoria e pensão e seus respectivos fundos de pensão, 2006. Dissertação (Mestrado em Contabilidade), - Curso de PósGraduação em Ciências Contábeis, Universidade de Brasília, Brasília, 2006.

CREPALDI, Silvio Aparecido. Auditoria Contábil, Teoria e Prática. 3. ed. São Paulo: Atlas, 2004.

DRUCKER, Peter F. Administrando em tempos de grandes mudanças. São Paulo: Pioneira, 1995.

ESCULDER, Sergio A. Loureiro e TINOCO, João Eduardo Prudêncio. O Conselho Fiscal e a Governança Corporativa: Transparência e Gestão de Conflitos. In: $8^{\circ}$ Congresso USP Controladoria e Contabilidade, 2008, São Paulo. Anais... São Paulo: FEA/USP, 2008. CD-ROM

FÉLIX, Cláudia Lima. REGIME PRÓPRIO DE PREVIDÊNCIA E ASSISTÊNCIA SOCIAL: uma análise do grau de conhecimento que o servidor público do Município do Rio de Janeiro detém em relação às informações gerenciais do regime previdenciário municipal. 2009. 180 f. Dissertação (Mestrado em Ciências Contábeis) - Curso de Pós-Graduação em Ciências Contábeis, Universidade Estadual do Rio de Janeiro, Rio de Janeiro, 2009.

FIGUEIREDO, Sandra; CAGGIANO: Paulo César. Controladoria Teoria e Prática. 3. ed. São Paulo: Atlas, 2005.

GARCIA e SOUZA, Thelma de Mesquita. Governança Corporativa e conflito de interesse nas sociedades anônimas. São Paulo: Atlas, 2005.

HU, Yuwei. Is there a link between pension fund assets and economic growth? A crosscountry study. London, UK. Brunel University, 2006. (Economics and finance discussion papers from economics and finance section, Brunel Business School). Disponível em: http://www.brunel.ac.uk/329/efwps/0611.pdf. Acesso em 28 fev 2009.

IBGC, Instituto Brasileiro de Governança Corporativa. www.ibgc.org.br

KLAPPER, R. LOVE, I. Corporate Governance, investor protection, and performance in emerging markets. Journal of Corporate Finance, v.10 p. 703-728, 2004. Disponível em: http://www.ideas.repec.org/p/wbk/wbrwps/2818.html. Acesso em 23 abr 2009.

LODI, João Bosco. Governança Corporativa. Rio de Janeiro: Campus, 2000. 
LOPES, Andréa. A Estrutura de governo no sistema de previdência complementar. In: $1^{\circ}$ Encontro dos Profissionais de Contabilidade das EFPC's do Norte/Nordeste. Set. 2005. Anais... Salvador: ANCEPP, 2005. CD-ROM.

MARTINEZ, Wladimir Novaes. Curso de Direito Previdenciário, Tomo IV Previdência Complementar. 2a Edição. São Paulo: LTr, 2002.

MARTINS, Gilberto de Andrade. Estatística geral e aplicada. 3. ed. São Paulo: Atlas, 2005.

MONKS, Robert A. G. MINOW, Nell. Corporate Governance. 3. ed. United States. 2004.

OLIVEIRA, Liliam Rodrigues de. PONTE, Vera Maria Rodrigues. O Papel da Controladoria em Fundos de Pensão. In: XII Congresso Brasileiro de Custos. Santa Catarina. 2005. Anais... Santa Catarina: ABC, FEA/USP, 2005. CD-ROM.

PAGLIARINI, Aparecida Ribeiro Garcia. Manual de Práticas e Recomendações aos Dirigentes das Entidades Fechadas de Previdência Complementar. São Paulo: SINDAPP, 2006.

PUNSUVO, Fábio Riberi; KAYO, Eduardo Kazuo; BARROS, Lucas Ayres Barreira de Campos. O Ativismo dos Fundos de Pensão e a Qualidade da governança Corporativa. Revista de Contabilidade e Finanças. USP. São Paulo, v.18, n.45, p. 63-72. Set/Dez 2007.

RIECHE, Fernando Ceschin Gestão de Riscos em Fundos de Pensão no Brasil: Situação Atual da Legislação e Perspectivas. Revista do BNDES, v. 12, n. 23, p. 219-242, jun. 2005.

RODRIGUEZ, Gregório; SEGRETI, João Bosco. Governança corporativa no Brasil - porque as empresas relutam em aderir às boas práticas boas práticas de governança. Disponível em: <http://www.uff.br/adm/pggt/monograf.htm>. Acesso em: 02 abr 2009.

SHLEIFER,Andrei; VISHNY, Robert. Large shareholders and corporate control. Journal of Political Economy, nº 94, 1986.

SILVA, André Luiz Carvalho da. LEAL, Ricardo pereira Câmara. Governança Corporativa: evidência empírica no Brasil. São Paulo: Atlas, 2007.

SILVA, Dionísio Jorge da. A Importância do Compliance. 2006. Disponível em: $<$ http://www.ancep.org.br/artigo> . Acesso em: 23 abr. 2009. 
SILVA, Dionísio Jorge da. Análise Contábil nos Fundos de Pensão. Brasília: Consultorys Consultoria, 2007.

SILVEIRA, Alexandre di Miceli da. Governança Corporativa e estrutura da propriedade: determinantes e relação com o desempenho das empresas no Brasil. Tese (Doutorado) - FEA/USP, 2004.

SILVEIRA, Maria Lizete da. O impacto dos padrões corporativos de ética, governança corporativa, responsabilidade social, sustentabilidade e transparência na volatividade das ações de bancos latino-americanos, 2006. Dissertação (Mestrado em Ciências Contábeis) - Pós-Graduação em Ciências Contábeis, Universidade de Brasília, Brasília, 2006.

STEPHANES, Reinhold. Reforma da previdência sem segredos. 2. ed. São Paulo: Record, 1999.

SOUZA, João Bosco de. Sistemas de informação e riscos em fundos de pensão, 2008. Dissertação (Mestrado em Engenharia de Produção) - Pós-Graduação em Engenharia de Produção, Universidade Federal de Pernambuco, Recife,2008.

THOMPSON-FLORÊS, Eliane Aleixo Lustosa. Governança Corporativa no Brasil e o Papel dos Investidores Institucionais, 2004. Tese (Doutorado em Engenharia de Produção) - PUC- Rio, Rio de Janeiro, 2004. 
